\title{
Correction to: Osseous ingrowth in allogeneic bone blocks applied for vertical bone augmentation: a preclinical randomized controlled study
}

\author{
Tobias Moest ${ }^{1}$ - Johanna Frabschka ${ }^{1} \cdot$ Marco Rainer Kesting ${ }^{1} \cdot$ Christian Martin Schmitt $^{1} \cdot$ Gesche Frohwitter $^{1}$. \\ Rainer Lutz ${ }^{1} \cdot$ Karl Andreas Schlegel $^{1}$
}

Published online: 24 July 2020

(C) Springer-Verlag GmbH Germany, part of Springer Nature 2020

Correction to: Clinical Oral Investigations. https://doi.org/10.1007/s00784-019-03151-0

In the article by Moest et al., entitled "Osseous ingrowth in allogeneic bone blocks applied for vertical bone augmentation: a preclinical randomised controlled study." [Clin Oral Investig. 2019 Dec 11. Epub ahead of print], human bone blocks and autologous porcine bone blocks were used in a porcine model. The term "allogeneic blocks" was used throughout the text to refer to the clinical use of "allogeneic blocks" in humans, which represents an inaccurate terminology of the applied biomaterial. Due to the application of the human bone blocks in the porcine model the terminology for the applied bone blocks changes from an "allogeneic" to a "xenogeneic" based biomaterial, which we want to emphasize especially in connection with the interpretation to generated results.

In order to avoid any misunderstandings or misinterpretations of the generated data - particularly with regard to inflammation, increased connective tissue formation and block loss - it should be highlighted that the applied human bone blocks represent a xenograft in the used animal model.

Publisher's note Springer Nature remains neutral with regard to jurisdictional claims in published maps and institutional affiliations.

The online version of the original article can be found at https://doi.org/ 10.1007/s00784-019-03151-0

Tobias Moest

tobias.moest@uk-erlangen.de

1 Department of Oral and Maxillofacial Surgery, University of Erlangen-Nürnberg, Glueckstraße 11, 91054 Erlangen, Germany 